\title{
Theory and practice of modeling gerontological education
}

\author{
Tatiana Y.Lomakina, ${ }^{1, *}$ \\ ${ }^{1}$ ISED RAE, Centre of research of lifelong learning
}

\begin{abstract}
On the basis of the basic principles of andragogy and famous models of education A model of education space on the basis of the basic principles of andragogy and famous models of education, created on the basis of a non-state University to persons of the third age is presented in the article
\end{abstract}

\section{Introduction}

Lifelong education provides every individual with conditions for free development of their educational, intellectual and activity-related opportunities throughout life [1]. Lifelong education is interpreted not as an administrative combination of diverse education institutions into an integrated system but as a wellthought out variable system of education services which enables an individual to avail himself or herself of these services in line with his or her personal needs and demands in different periods of life. Moreover, education programs geared to the principles of continuity and integration are of huge social significance since they facilitate: (a) natural reduction of learning duration and costs of specialist training; (b) systematization of knowledge at every next education level; (c) deep absorption of knowledge thanks to the module- based structure of education programs; and (d) succession of knowledge thanks to consistency between all levels of education.

Closely connected with lifelong education are the issues of adult learning. They are aimed at updating their knowledge and/or changes in qualifications. All of these students share a desire to benefit from the learning opportunities for the purpose of career advancement, improved financial position, changes in social status. This new group of students in the near future will be the rule, and training will be considered as an active process, covering the entire professional life of a person, preparation for employment and job descriptions, not just a diploma. At the same time, alternating periods of training and work requires a change in the educational process. His feature is, first of all, that the object of educational activity - adult.

It assesses, analyzes, selects the knowledge and internally adjusts them based on their experience, motivations, values, which, in turn, caused the stages of maturation and social status. Further enhancing the role of lifelong learning, adult education, which are characteristic for the foreign countries, and Russia related to global changes and the transition from post- industrial to an information society, suggest as the leading type of de-yours elf human work with the information as by its very nature, such activity is a form of education.

\section{Gerontological Education}

"Lifelong" learning of adults is the domain of andragogues. The term "andragogy" was first used by the historian of education K. Kapp in his book about pedagogical views of Plato (1833) to denote a special area of pedagogy. The second half of the 20th century can be considered the golden age of andragogy. It is associated with the name of M. Knowles, the prominent American practitioner and theoretician of adult education, who referred to andragogy as the science and art of adult learning and identified the following basic principles of this area: (a) adult learning should address a specific problem; (b) adult learning should take into account and be based on learners' experience; (c) experience and knowledge acquired from learning should be significant for a learner; (d) the learner should have the opportunity to verify the content taught; (e) learning goals should be set up in cooperation between a learner and an andragogue; (f) a learner should receive feedback about achievements against learning goals [2]. Innovative forms, methods and techniques for the implementation of modern social policy for third age individuals are, first of all, about the development and implementation of the concept of gerontological policy and, in particular, in the context of this analysis, gerontological education as a need for modifying the current model of social protection and support of elderly people.

In our opinion, a socially adapted retired person is a socially active individual who acts in the context of his or her own choice as the writer of the script of his or her life and relies on his or her personal and professional experience and intellectual capabilities to the greatest extent possible. Therefore, adaptation to a new education space, extension of the opportunity for third age persons 
to acquire additional knowledge, skills and abilities and enhancement of their motivation toward learning activity are possible through civic institutions (public organizations) and the non-government education sector, which will be virtually able to take into account all the specifics of Russian gerontological education by creating necessary education models.

Gerontological education is designed with due consideration to the development of personal education paths for third age individuals on the basis of the principles of continuity, individualization and variability. International practice of third age learning shows that the implementation of a variable system of gerontological education creates an optimal environment for building an education space for the elderly. Variability manifests itself in the op portunity for learners to choose education areas in line with their aptitudes and personal capabilities and also in the creation of a specialized education space taking into account the specifics of third age people. The education space is based on the provision of optimal psychological and pedagogic.il conditions for selfactualization of every learner and satisfaction of their educational interests in this period of life. Practice shows that the implementation of variable person-centered approaches to learning requires that the following conditions are met: first, ensure that every learner has freedom of choice of his or her own "path" in gaining knowledge, skills and abilities; second, create in an education institution a learning environment which will promote a cultural and creative flourish of individuality for every learner; third, determine teaching methods and techniques in accordance with age- specific characteristics of third age people; and fourth, extend and improve the quality of pedagogical technology in teaching third age individuals on the basis of information achievements, including distance learning technology.

\section{Education models}

Russian education science does not provide an unambiguous interpretation of the concept of "education model"; therefore we will use this definition in the sense of a special method of learning management with an emphasis on the dominating group of the teaching methods, forms, aids and techniques used. An analysis shows that pedagogical practice reflects the following models of education:

The model of an education institution as a government department entity. which reflects the competent autonomy of economic sectors in the country and aims at training specialists belonging to an executive department which imposes certain strict and centralized requirements on them;

The model of developing education (V. Davydov, V. Rubstov, etc.), where synthesis of different systems of learning and education allows for a quick solution for training the necessary workforce to cater to the needs of a transforming society;

The traditional education model (J. Mageau, L. Creau, G. Kapel, D Ravitch, etc.) reflects the paradigm of systematic academic education as a means of transferring elements of past culture to a learner. By mastering basic knowledge, skills and abilities a learner is to advance in development of his or her "selfhood" and use it as a basis for acquiring knowledge, skills and abilities of a higher level;

The rationalistic education model (P. Bloom, $\mathrm{R}$. Gagne, B. Skinner etc.) is aimed at adapting a learner to the existing society where any learning program can be translated into a "behavioral" aspect of knowledge, skills and abilities that the learner has to master. In this model, education is reduced to simple drilling, since pedagogical search, cooperation, individuality, responsibility and creativity are minimized and a teacher follows a strictly predetermined pattern;

The phenomenological education model (A. Maslow, A. Combs, C Rogers, etc.) takes into account individual psychological characteristics of a learner's development. An emphasis is made on self-cognition and selfdevelopment of a learner's personality and maximum individual freedom,

The non-institutional education model (P. Goodman, I. Illich, J. Goodlad, F. Klein, etc.) involves organization of education outside social institutions. This education is delivered on a distance basis, through the Internet or other means of indirect transfer and acquisition of knowledge;

the culturological model of upbringing and education content (M. Skatkin, I. Lerner, V. Kraevsky, S. Ivanona) is focused on pedagogical adaptation of culture in historical succession with its eternal problem of the moral ideal.

Let us supplement the above list of conventional education models with a model which began to develop in the course of social democratization and transition of the economy to market relations and is oriented toward individual freedom and right of choice, enhancement of spirituality and self- identity of ethnoses taking into account sharp economic polarization of society. This is the innovative education model (V. Vaschenko, V. Deliya, V. Lazarev, T. Lomakina, M. Potashik, I. Chechel, I. Tsaturova, etc.) which is based on the person-centered education paradigm providing for the implementation of individual learning paths by means of content- and levelspecific differentiation of education programs in the context of field-specific specialization.

I. Smirnova identifies eight innovative learning models, as well as key features and characteristics of the traditional learning model. The most acceptable innovative learning models for gerontological education within the framework of a Third Age University are the models of module-based and distance learning.

\section{Levels and models of the education space}

We have built a model of the education space on the basis of a non-government higher education institution (HEI) for third age individuals. This model optimizes organizational, didactical, teaching, methodological, scientific and human resources and efforts of a HEI to reach the goals of high quality and efficient training of 
this age cohort. The developed model is based on the following statements: (a) the main objective of the developed paradigm and concept of gerontological education is to create an environment for meeting the educational demands of third age people as much as possible, with due consideration of the knowledge, skills, abilities and individual characteristics of representatives of this age group; (b) building a flexible organizational and staff structure which allows for quick reshuffling and modification of the staff in the course of learning for the benefit of the learning process; (c) seeking to build a like-minded group when selecting staff and faculty members; (d) searching for non-traditional teaching techniques and providing the learning process with educational packages; (e) building a creative environment for teachers and learners.

Building the model of gerontological education space of a nongovernment HEI includes the following steps:

Analytical (step 1), which involves reviewing the condition of the gerontological education system in the country and defining a problem field; drawing on international and domestic experience in educating people of this age cohort; identifying and finding innovative ideas and principles to generate a potentially effective pedagogical innovation.

Creating a concept (step 2) is descried by developing a strategy for the operation of the gerontological education environment in a nongovernment HEI in the framework of a Third Age University in the form of building a new paradigm and concept of learning for this age group.

Pedagogical support of the concept (step 3) defines a strategy and tactics of deployment of the model of the gerontological education environment in a nongovernment HEI in the actual operation and development of pedagogical support of education, as well as development of a teaching package and selection of teaching staff who are experienced at working with this category of people (or retraining of faculty members), and other activities.

Outcomes of activities (step 4) involve achieving the ultimate outcome, including meeting educational demands of third age individuals.

Monitoring the quality of educational services for third age people (step 5) is focused on establishing monitoring the quality of learning of third age individuals in a nongovernment HEI.

In our study, we regard the model of gerontological education space in a HEI as an open system which allows for building efficient contacts and links with organizations, enterprises, administration, the academic community, etc. and efficiently implements the concept of the institute. The established feedback will help adjust curricula and organization of educational work with third age persons. The core of the model is teacher-learner cooperation motivated toward active substantive learning of the education process. They are involved not only in subject-subject relationships, but also in the specific creative process of interaction which develops relevant competencies (key, basic and special). A special characteristic feature of this process is creative thinking.

The substantive component of the model is aimed at: (a) teaching, forecasting, modeling, predicting and anticipating an outcome in the course of the proposed professional activity; (b) teaching knowledge and skills on the basis of a forward-looking forecast of their development; (c) developing abilities of finding conceptual meanings of a discipline learned for the purpose of their application in professional activity; (d) utilizing capabilities of information, computer and multimedia resources; developing specific education technologies; and (e) improving cognitive activity of learners. The technological component of the model takes into account the nature of developing professional competencies and specifics of developing spiritual and moral qualities, which predetermines the choice of specific techniques for this age group.

\section{Training techniques}

Modern teaching techniques can be used provided a HEI has a well developed training and material resource base. Its main characteristics include the following: high availability of computer resources and application of computer software in developing professional competencies; free Internet access; availability and use of local networks in learning activities, availability of a modern library and its electronic version; a permanent website of a HEI to be used to access the World Wide Web and provide distance learning for students; creation of specialized classrooms and laboratories provided with modern equipment and telecommunications for learning, a printing office, simulators, etc. Distance learning is an innovative technology of learning in the Third Age University context. In open education, nearly all processes of generation, transfer, control, access to and absorption knowledge are technologized and supported by relevant didactic materials, such as training courses, learning guidance, methodologies, etc.

Practical experience in developing distant learning courses enables us to define the main principles of developing electronic course: (a) cost efficiency production of electronic courses should be cheap and allow for their fast creation and renewal; (b) modulebased structure of learning content which allows for designing individualized learning programs for every learner subject to the level of their attainment and needs; (c) a convenient unified user interface filled with elements inherent in the conventional learning process (a lecture room, a blackboard, etc.) and unified technological techniques and display images for switching between different courses; (d) personalization elements to provide the effect of face-to-face collaboration between a learner and a teacher (photo, sound, video); (e) use of multimedia technology to facilitate better memorization and perception and incorporation of means of psychological relaxation (music, animation, etc.) into learning content; (f) use of hypertext structure both in the conceptual part of the training content (definitions, key words, etc.) and in the logical structure of its presentation (sequence and interrelations between modules); (g) use of educational information technology for teamwork in interactive communication to enable teacher - student, student - 
teacher and student - student communications; (h) use of various methods of delivery depending on the category of learners: Internet, a corporate, local network or a laser disc, and in particular, delivery of learning content with the use of open Internet standards which do not require a learner to install any additional software; (i) teaching techniques.

In addition to traditional teaching techniques, there are distant learning techniques which are usually divided into the following types: case-based, TV-based and network-based techniques. The case-based technique involves the use of module-based structure of training materials. They are organized into a special package (a "case" or "portfolio") and sent (handed over) to a learner on paper, magnetic media and/or a laser disc. The learner then studies these materials on his or her own and contacts specially trained advisory teachers for clarifications from time to time. Each training course is provided with a textbook or a training guide, syllabus and methodological guidelines which help the student to learn the training content. The module- based principle of building syllabuses helps to successfully match learners' needs and capabilities.

$T V$-based techniques are based on the use of TV lectures with consultations of advisory teachers in the location of the learner's residence, by telephone and via the Internet. Distant learning on the basis of interactive (two-way) TV has been growing more popular in recent years. This form of distant learning is intrinsically interactive and can certainly be regarded as a rather promising form, if not for mass learning, then at least for skills upgrading.

Network-based techniques involve the use of the Internet both for delivery of education materials to learners and for interactive collaboration between a teacher and learners. In practice, network-based techniques can be implemented in the following main modifications: using networks to exchange text files only; using networks to share both texts and multimedia content, in particular on an online basis and also with the use of computer teleconferencing. This type of distance learning management clearly provides enormous didactic opportunities for all levels of education.

Therefore, a diversity of technological solutions will ensure maximum openness of education for all wishing and able to learn, and an opportunity to learn at any age and at any distance from education institutions.

\section{Pedagogical conditions for implementation of gerontological education}

The learning environment in an education institution contributes to the development of a HEI management system, as well as teaching, educational, scientific and upbringing work in general. Managing a HEI is a priority area of pedagogical support of the education space. It accommodates the comprehensive generation and implementation of the concept of training and upbringing aimed at developing creative thinking in participants of the education process. The system of selection and assessment of the quality of human resources in a HEI should meet imperatives of the time and be developed not only toward raising scientific and pedagogical skills of faculty members, as is traditionally the case in the Russian education system but also toward developing key market competencies among the staff.

It is necessary to develop a special customer-oriented approach in HEI's operations, which will help maintain loyalty of the existing customers and acquire prospective ones. Functions of the human resources subsystem include recruiting highly-skilled teachers and specialists who are proficient in modern information technology and are experienced in deploying them in the education process, and training them to become faculty members and employees of the education institution. Staffing of professional education programs for third age individuals currently includes: (1) traditionally highly- skilled staff who deliver teaching in fundamental disciplines; (2) teachers who deliver teaching in relatively new disciplines in the framework of general professional disciplines, special groups of disciplines and specialty disciplines within professional education programs for people of this age group. It should be noted that gerontological education, as well as Russian education as a whole, faces considerable difficulties with staffing of the training process both in terms of quantity and quality. These problems are especially sharp in regional education institutions; therefore the transition to distance learning of disciplines will help reduce the shortage of personnel in the system of gerontological education.

The material and technical subsystem of gerontological education should include computer and facsimile equipment, telecommunications devices, classrooms and counseling rooms, and also facilities that are not mandatory for conventional education, such as a multimedia laboratory, a TV studio, a laser and magnetic disc recording and replication center, audio recording center, etc.

The information and methodology subsystem provides for: (a) collection, accumulation and systematization into databases of information about demands of the labor market, production and education; (b) collection and processing of information about the learning process progress (data about enrollment and graduation of learners, accomplishment of academic schedules, recording of work performed by advisory teachers, etc.); (c) accumulation of educational materials for all types of classes, consultations, tests (the courseware) in a database; (d) maintaining a database of a list (catalogue) of educational products and services (textbooks, testing systems); (e) collection and processing of current data from different gerontological education institutions, such information about the learning process, needs for education materials and development of new syllabuses and courses. Courseware of professional education programs for third age individuals includes conventional textbooks, training and methodological guides, tests and assignments, etc.; electronic educational packages for a number of social disciplines developed in HTML format, which is standard for the Internet, educational films, digital audio and video lectures, etc. The portal is designed to provide conditions for the development of an 
open education system on a qualitatively new level.

The financial and economic subsystem of gerontological education is designed to be more flexible and variable in operation. This is driven by the fact that an individual education path of a learner has to be rationally organized and supported by an estimate of economic costs required to implement it.

The marketing subsystem is focused on discovering needs for education, dealing with promotion and building databases of orders for training and retraining of individuals. Therefore the marketing subsystem is designed to cater, as efficiently as possible, for the needs of: an individual in education; an education institution in development and welfare of its staff; firms and other customer organizations in growth of human resources; and society in extended reproduction of the aggregate personal and intellectual potential.

The study shows that open education is implemented in the following institutional forms: (a) a distance learning department in a traditional education institution; (b) open education institutions; (c) consortia of education institutions; (d) TV schools; (e) virtual education institutions. Let us briefly discuss their purposes.

When it comes to distance training of third age individuals, the most efficient way to work with people of this age cohort is through distance learning departments in traditional education institutions and through open education institutions. Let us note that the most widespread form in contemporary Russian open education is individual divisions (distance learning departments or institutes) in conventional education institutions. Furthermore, they have the necessary experience at solving organizational and managerial tasks associated with the education process. With their very strong faculty membership, conventional universities have significant capabilities to develop stateof-the- art electronic training courses for third age persons. On the other hand, distance learning departments enable conventional education institutions to extend the range and increase the scope of educational services offered to different categories of individuals, and also enhance competitiveness of their graduates in the Russian and international markets.

Open education institutions are intended to offer open distant education services to the public. This task determines the organizational structure, faculty membership, technical and auxiliary educational staff and administrators.

A consortium of education institutions is a new form in the system of education. It is developed on the basis of modern educational information technology. A consortium provides communication and administrative services for distant learning courses developed by its member education insti tutions. It provides an opportunity to receive degrees and certificates from the education institutions comprising the consortium on a distance basis. This institutional model is extremely relevant for the development of Russian open education.

$T V$ school is a form of distance higher education which is based on building a much stronger (than in the case of a consortium of education institutions) pool of
HEI resources. This form is rather widespread abroad. A TV school offers collaboration between a few independent education institutions on the basis of integrated curricula. It develops and implements distance learning courses using the faculty, equipment and other resources of conventional universities. Unlike a consortium, a TV school awards degrees and issues its own diplomas instead of education certificates of cooperative schools. So far the international practices of TV schools have not been disseminated to the Russian market.

In the recent years, new organized education entities known as virtual education institutions (virtual universities and their divisions) have been developing on the basis of network technology. These education entities implement the principles of open education and may have no attributes of conventional education institutions, such as "physical" premises, classes, laboratories and student dormitories. Training may be delivered both using traditional methods and via computer networks, such as the World Wide Web (Internet) or a corporate network (Intranet). Such an education institution has a two-level structure comprised of the central university and its regional division.

The functions of standard software used by a virtual university can be divided into two categories: support of the educational information environment and support of interaction between this educational information environment and other educational environments. The first group of functions includes: (a) generating data to be placed in the open part of the educational information environment (News, Contacts, Project Information, etc.); (b) creating and removing virtual divisions of education institutions; (c) creating catalogues (of education institutions, information and other resources, professions, etc.); (d) consulting users on methods of work in the educational information environment; (e) generating system-wide statistics, etc. The second group of functions includes: (a) generating and updating account information about the educational information environment in a database; (b) realizing a replication procedure to other servers of the educational information environment; (c) collecting, pre-analyzing and communicating observations of the educational information environment users to the developers, etc.

It is evident that the open education system is designed to encompass the entire territory of Russia and smoothly integrate into the international education system.

Both international and national experiences show that open education is much cheaper than traditional one. The costs of organizing open education are reduced due to a few factors, the main of which is a smaller percentage of faculty members in the staff of an education institution (30\% instead of $50 \%$ in a conventional education institution) [3]. For example, a Russia-wide experiment in distant learning has shown that the gain is $10-20 \%$ to $50 \%$ of costs inherent in traditional full-time learning, and the more large scale open education is, the lower costs will be. The reduced cost of learning in open education is an important positive factor for the development of gerontological education, because there 
is a certain need for additional open education among third age people. The cost efficiency of the open education system will be further improved by: (a) extensive advertising of open gerontological education programs targeting consumers of high quality and relatively cheap educational services; (b) flexible pricing: a significantly lower tuition fee for open learning with an opportunity to receive additional, individual open educational services for an extra charge.

Implementation of the proposed model of gerontological education will help solve the following main problems: (1) create integrated courseware for teaching all disciplines including training programs and subject-specific syllabuses, textbooks, training aids, etc. for all levels of gerontological education; (2) eliminate the shortage of skilled teaching staff which is especially relevant to regional education institutions; (3) build an effective advanced training system for teachers working with third age individuals; (4) involve the scientific and pedagogical community and gifted young people in research on gerontological education; (5) ensure continuity of education based on the principles of integrity and succession of learning at all levels of education avoiding overlaps and duplications between learning programs of different levels; (6) ensure a person-centered approach to learning by providing an opportunity for building an individual education path; (7) ensure accessibility of gerontological education by deploying distance learning technology, (8) consolidate regional HEIs around a leading education institution in order to enhance scientific, research and methodological work to ensure the high quality of gerontological education.

\section{Conclusion}

Our study has shown that the main principle of development of Third Age Universities is openness of the gerontological education system. The modern concept of open education is built on providing every person with free access to educational resources. Analysis of Russian and foreign experience in open education has enabled us to identify the main criteria of the development of a large-scale, multi-level and complexly structured system of gerontological education as follows: first, a systemic nature, which involves pooling material, technical, teaching, informational and human resources of education institutions of different levels to operate in close interaction with each other and with authorities, institutions and organizations in the education and social spheres; second, succession, both vertical and horizontal, i.e. not only between different stages and levels of education but also within individual educational programs; third, variability, which involves a differentiated approach to the organization and content of training depending on profession, specific conditions and needs of society and a region; fourth, individualization of training which allows for the implementation of the person- centered learning model on the one hand, and creation of the necessary environment for lifelong learning on the other; fifth, a combination of the fundamental and practical aspects of learning in order for a learner to be both professionally competent and able to make decisions in any unpredictable social situation; sixth, social efficiency by achieving a high level of matching between the quality of education and social demands; seventh, economic efficiency which implies return on investment in gerontological education. Training of people belonging to this age cohort should be offered both in distant and conventional learning modes.

\section{References}

1. T.Yu. Lomakina, Diversifikatsiya professional'nogo obrazovaniya (TsPNO ITOP RAO, Moskva, 2000)[In Rus]

2. L.A. Nikolenko, Problemy identichnosti: chelovek $i$ obshchestvo na poroge tret'ego tysyacheletiya (ROO «Sodeistvie sotrudnichestvu Instituta im. Dzh. Kennana s uchenymi $\mathrm{v}$ oblasti sotsial'nykh i gumanitarnykh nauk», Moskva, 2003) [In Rus]

3. Sostoyanie, potrebnosti $i$ perspektivy razvitiya distantsionnogo obrazovaniya $v$ Rossii $i \quad z a$ rubezhom (2000) [In Rus]

4. L.A. Andreev, V.A. Soldatkin, Distantsionnoe obuchenie: sushchnost', tekhnologiya, organizatsiya (MESI, Moskva, 1999) [In Rus] 